\title{
CONFLICTO ENTRE LOS REGIDORES $Y$ EL CORREGIDOR DE CORDOBA A PRINCIPIOS DEL XVIII
}

por

José-Manuel de Bernardo Ares

Profesor de Historia Moderna de la Universidad de Córdoba

SUMARIO: I. INTRODUCCION.-II. OFICIOS DE LA CIUDAD.III. CONSECUENCIAS LOCALES DEL ABSOLUTISMO BORBONICO.-IV. SORTEO Y NOMBRAMIENTO DE EMPLEADOS. V. ARRENDAMIENTO DE OFICIOS.-VI. RECURSOS DE LOS CAPITULARES. - VII. FIRMEZA DEL CORREGIDOR. - VIII. CONCLUSION.

\section{INTRODUCCION}

Durante los cinco años que van de 1717 a 1722 tuvo lugar en Córdoba un enconado enfrentamiento entre el Corregidor y la mayor parte de los Caballeros veinticuatros del Municipio por causa de los oficios enajenados de la Corona en favor de la ciudad. El problema planteado no estaba en la propiedad de los oficios por parte del Concejo, lo que era indiscutible para ambas partes litigantes, sino en el modo de proveerlos y en los destinatarios de las rentas que producían. Para los Regidores o Caballeros veinticuatros (1) los titulares anuales de los referidos oficios debian de ser

(1) En Andalucía a los Regidores se les llamó Caballeros veinticuatros, por ser 24 en sus orígenes los que integraban el Regimiento. L. G. de Valdeavellano: Curso de Historia de las instituciones españolas. De los origenes al final ide la Edad Media, Madrid, 1975, 550. En adelante, nosotros utilizaremos ambos términos indistintamente. 
nombrados por ellos mismos, de acuerdo con la costumbre local, y los beneficios económicos repartidos entre el que lo ejercía y el propio Regidor que le cabía en suerte la facultad de elegirlo. Por el contrario, el Corregidor, cortando de raíz toda intervención de los Caballeros veinticuatros, intentaba sacar los oficios a la subasta pública para arrendarlos al mayor postor e ingresar el montante de sus rentas en las arcas municipales.

La relevancia histórica de este hecho estriba en el conflicto jurídico-institucional entre el poder local, representado por los Caballeros veinticuatros, y el absolutismo del Monarca que, a través del Corregidor, quería reforzar el aparato del Estado, ya endeble con el último de los Austrias y considerablemente zarandeado por los irreparables avatares de la Guerra de Sucesión (2). A este aspecto político hay que añadir otro de marcado carácter económico: no sólo se aumenta con las aportaciones de estas rentas el caudal de propios del que dispone el Corregidor - léase el Monarca-, sino que se seca el hontanar financiero de la oligarquía local, que, si bien no percibía cantidades elevadas, ejercía un control económico al manejar un instrumento fiscal de gran incidencia en la vida urbana (3).

La fuente primordial utilizada para la articulación de este trabajo la constituye un expediente de 43 folios conservado en el $\mathrm{Ar}$ chivo Municipal de Córdoba (4). Distinguimos en él dos partes fundamentales. En una se contienen los autos, recursos... a que da lugar el susodicho conflicto; en la otra se hace un detenido análisis sobre el modo de proceder anterior a 1717, en que se promulgó una Real Provisión, punto de partida del pleito desencadenado, y que traduce la nueva actitud del poder central en relación con las in. veteradas oligarquías urbanas. Estas seguirán detentando exclusivamente el poder local hasta la reforma carlotercista de 1766 (5),

(2) «Con la proclamación de Felipe V como Rey de España comenzó a perfilarse la tendencia a concentrar, en forma absoluta, el poder político en la persona del Rey». G. ANES: El Antiguo Régimen: Los Borbones, Madrid, 1975, 297. Sobre el proceso de centralización en el xvirI aporta una idea muy precisa M. ARTOLA: Los orígenes de la España contemporánea, Madrid, 1975, I, 30-31.

(3) F. TOMÁs Y VALIENTE pone de relieve el carácter aristocrático del Regimiento de Salamanca. «Las ventas de oficios de Regidores y la formación de oligarquías urbanas en Castilla (siglos xviI y XviII)", en Actas de las I Jornadas de metodología aplicada de las ciencias históricas. III. Historia moderna, Santiago de Compostela, 1975, 551-68.

(4) AMCO: Oficios enajenados de la Corona, Sec. 2:, Serie 18, Caja 62, Leg. 61, documento 13. (En adelante citaremos abreviadamente indicando tan sólo el número del documento.)

(5) Acerca de la reforma municipal acometida por Carlos III, vid. el análisis 
pero reciben ahora, en los albores del xvirI, un primer zarpazo que recorta sus omnímodas atribuciones económicas.

\section{OFICIOS DE LA CIUDAD}

Antes de desarrollar el punto central del tema que nos ocupa, consideramos muy esclarecedor el precisar, aunque sea de una manera aproximativa, por la poquedad de las fuentes manejadas, cuáles fueron los oficios enajenados por la Corona en favor de la ciudad y que ésta tenía como propios en virtud de los correspondientes títulos y privilegios. El cuadro siguiente nos muestra, si no todos, al menos la mayor parte de los oficios que se ejercían en los años indicados, suficientemente distanciados entre sí para darnos una idea más o menos exacta de su permanencia durante la época moderna.

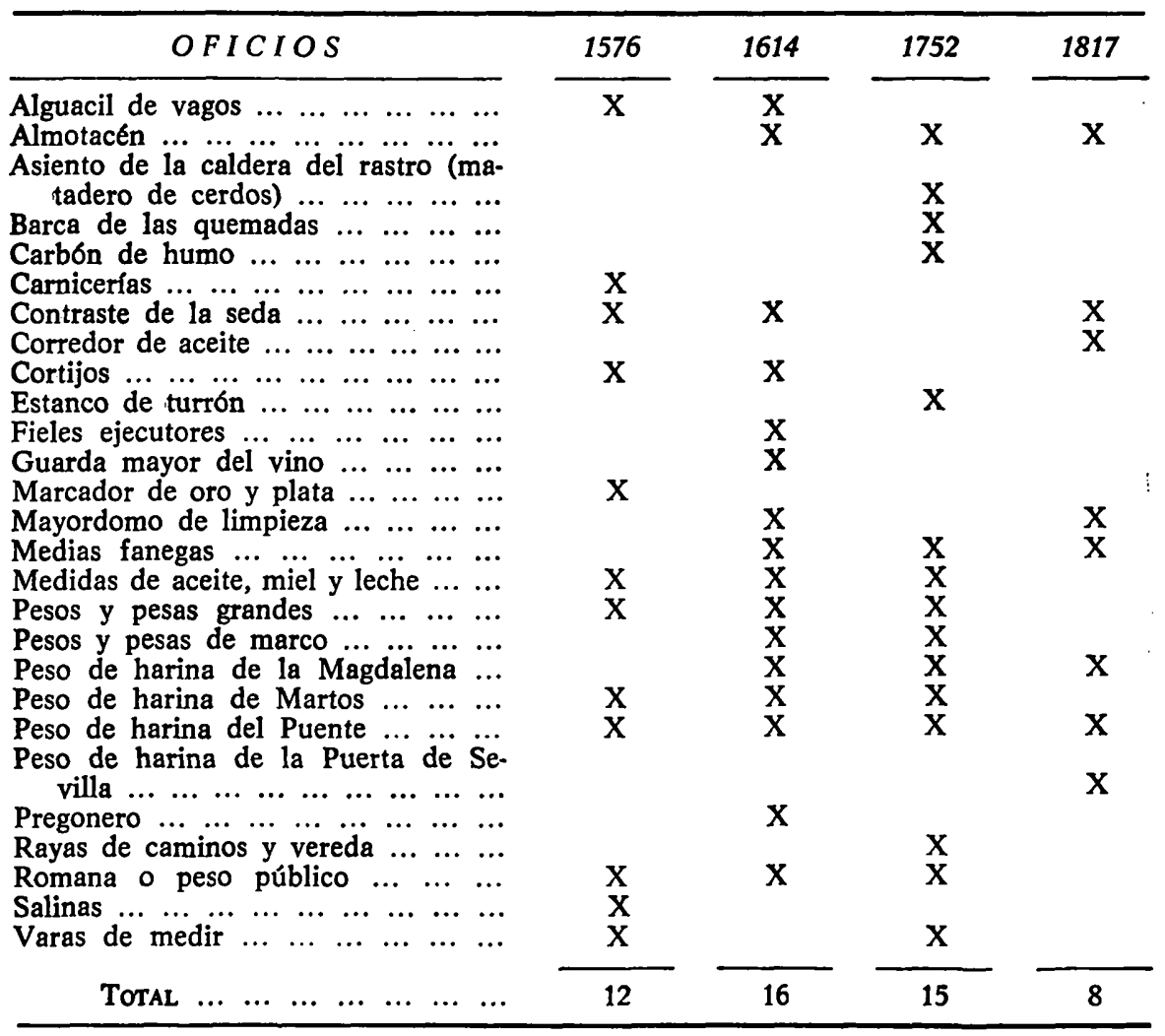

certero de A. Domínguez Ortiz: Sociedad y Estado en el siglo XVIII español, 1976, 471-75. 
Para los años 1576 y 1614 los oficios en uso, señalados con una cruz, están tomados del extracto del informe confeccionado para ilustrar históricamente sobre la cuestión debatida y presentado en Cabildo general el 4 de julio de 1718 (6). Del Catastro de Ensenada recogemos los datos correspondientes a 1752 (7). Y, finalmente, para 1817, nos servimos de una relación nominal que el Corregidor don Joaquín Bernard y Vargas mandó hacer para informar al Consejo qué propietarios de oficios existentes en la capital de Córdoba pagaban el Real valimiento (8). A la vista del cuadro anterior se deduce que los oficios propios de la ciudad - no los que se ejercían en ella, porque éstos eran muchísimos más (9)- oscilaron entre ocho y dieciséis, y los más permanentes fueron el de almotacén, fiel de medias fanegas, de medidas de aceite, de los pesos de harina. del Puente, Martos y Magdalena, y el fiel de la romana o peso público.

\section{CONSECUENCIAS LOCALES DEL ABSOLUTISMO BORBONICO}

¿Cuál fue el problema planteado por estos oficios pocos años después de terminar la Guerra de Sucesión? El nudo gordiano de la cuestión se centró exclusivamente en el modo de proveerlos. En los párrafos subsiguientes vamos a ver el proceso. Pero éste tuvo un hilo conductor que no puede pasarnos inadvertido, so pena de no entender adecuadamente las verdaderas dimensiones del conflicto. Lo que se ventiló realmente fue una pugna abierta por conseguir el dominio del poder local por parte del Rey a través de su Corregidor, en menoscabo de los proponentes Regidores, representantes del estamento noble más afortunado económicamente. El interés de Felipe $\mathrm{V}$ por allegar recursos y sanear la maltrecha Hacienda después de una extenuante y prolongada guerra es la otra cara de una misma realidad. Con todo, opinamos que, habida cuenta de la escasa cuantía de reales que proporcionaban estos oficios, al menos en el caso

(6) AMCO: Oficios enajenados de la Corona, doc. 13, fols. 4v. y 8r.

(7) AMCO: Catastro de Ensenada, Interrogatorio de la letra A, Sec. 12, Serie 5.;, T. 3., Leg. 45 , fols. $166 \mathrm{r} .-169 \mathrm{r}$.

(8) AMCO: Oficios enajenados de la Corona, Sec. 2.", Serie 18, Caja 62, Leg. 61, documento 21 , fol. $6 \mathrm{r}$. y v.

(9) El 18 de mayo de 1817 , en carta dirigida al Intendente de la Provincia de Cordoba, se indica que el número de oficios existentes en la capital es de 238. Ibid., folio $28 r$. 
de Córdoba (10), la faceta económica esconde el afán decidido del primer Borbón en hacerse de una forma efectiva con las riendas del poder a nivel local. La inminente creación de la figura del Intendente en 1718, y su rápida extensión por el entorno peninsular, le permitiría lograrlo plenamente (11).

El punto de partida lo señaló una Real Provisión dada en Madrid el 15 de septiembre de 1717. En ella, Felipe V, después de haber sido informado por el Fiscal del Consejo, don Tomás Melgarejo, sobre un pleito que se ventilaba en aquel alto organismo sobre si los oficios se debían arrendar para aumentar el caudal de propios o, por el contrario, sortearlos entre los Caballeros veinticuatros, quienes nombrarían usufructuarios particulares, recabó del Corregidor de Córdoba un circunstanciado informe del estado exacto de estos oficios en aquel momento (12).

\section{SORTEO Y NOMBRAMIENTO DE EMPLEADOS}

Al año siguiente se celebró un Cabildo general el 4 de julio, en el que se leyó una memoria minuciosa sobre el modo de proceder anterior sobre el particular. De su amplio contenido, a veces demasiado reiterativo, merecen destacarse tres puntos fundamentales.

Primeramente se citaba una Real Provisión de 6 de mayo de 1576 , que versaba sobre el voto secreto por suertes y se aludía a once capítulos acordados por la ciudad en el Cabildo del día 25 de mayo de 1576. En estos capítulos se estipuló que la elección y nombramiento de oficios se haría de acuerdo con las leyes y pragmáticas del Reino; que las calidades de las personas seleccionadas serían las exigidas por las Ordenanzas de la ciudad, y que el procedimiento a seguir consistiría en elegir por suerte - sortear - un Caballero veinticuatro, éste nombraría - nombrar - a una persona que él considerase idónea por su fama, edad, habilidad y suficiencia, $y$, por último, el Cabildo aprobaría o excluiría - aprobar o rechazar-,

(10) En 1752 el oficio de almotacén le proporcion6 a la ciudad por su arrendamiento 2.313 rs. anuales; los fieles de pesos de harina, 1.320 rs. entre los tres (Puerta del Puente, plazuela de la Magdalena y Martos); la romana pública y el estanco del turrón, 1.000 rs. cada uno. Los restantes empleos, consignados en el cuadro precedente, produjeron rentas inferiores a 900 rs. AMCO: Catastro de Ensenada, fols. 168v.-169r. Los ingresos por este concepto se elevaron a 9.087 rs. Cantidad muy pequeña si la comparamos con los 143.281 rs. y 2 mrs. que aportaban los arbitrios y los 100.800 rs. y 19 mrs. que producían los propios. Ibid., fols. 132r.-138v.

(11) G. ANEs: El Antiguo Régimen..., 315-20.

(12) AMCO: Oficios enajenados de la Corona, doc. 13, fols. 1r.-2r. 
mediante votación, el nombramiento hecho por el Regidor. Estas elecciones tendrían lugar todos los años en el Cabildo general celebrado el día de San Juan Bautista (13).

En segundo lugar se refiere al inadmisible intento de vender en 1614 los dieciséis oficios que poseía la ciudad por parte del Consejo de Hacienda, para lo que comisionó al licenciado Marcos de Torres. La estrechez financiera de la Real Hacienda aconsejaba esta medida extrema, que Córdoba no aceptó, como puso de relieve en el Cabildo celebrado el 9 de abril de 1615. Con el abono de 5.000 ducados, pagados en dos años y sacados de los arbitrios, la ciudad logró que no se le despojase de sus oficios, consiguiendo de Felipe III una escritura de asiento (1-VIII-1615) y un privilegio y título de los oficios perpetuados (15-VIII-1615) (14). Reconocida de iure, una vez más, la propiedad de los oficios, los Regidores cordobeses continuarían con su inveterada costumbre de nombrar "sus" candidatos para el desempeño de los mismos (15).

El tercer punto a destacar, y en la misma línea que los dos anteriores, lo constituye la Real Cédula de 12 de diciembre de 1712, por la cual se reconocía a la ciudad la perpetua propiedad de los oficios. Esto era tanto más importante cuanto que Felipe V, en su afán de quebrar el poder local que representaban las Regidurías perpetuas, creó la Junta de Incorporación, con el fin de agregar a la Corona un buen número de oficios otrora enajenados (16).

Teniendo en cuenta estos tres puntos de la detallada memoria, y en cumplimiento de lo mandado por la Real Provisión de 1717, el Corregidor de Córdoba, a la sazón don Gaspar Matías Salazar, dio un Auto el 6 de agosto de 1718, en el que se ordenaba hacer el informe circunstanciado que en aquella Real Provisión se solicitaba, pero, mientras tanto se decidiera otra cosa, "por ahora se prozeda a hechar las suertes de dichos oficios según se a practicado sin ignobar...» (17).

Por consiguiente, desde 1576 hasta 1718, los oficios pertenecientes a la ciudad se proveyeron en personas elegidas por los Caballeros veinticuatros a quienes previamente les había tocado en suerte, decidida por insaculación. Y para el susodicho Corregidor la Real

(13) Ibíd., fols. 4r.-7v. Todos los empleos eran anuales, excepto el de fiel romanero de las carnicerías que se ejercía durante dos años (fol. $5 \mathrm{v}$.).

(14) Perdido el primitivo título de 1615, se expidió en Madrid el 20 de febrero de 1636 un nuevo título de perpetuación de la propiedad de los oficios. Ibíd., fol. 24v.

(15) Ibid., fol. 8r. y v.

(16) Ibid., fol. $17 \mathrm{r}$.

(17) Ibid., fol. 20r. y v. 
Provisión de 1717 no suponía ninguna alteración, por cuanto juzgó que lo único que se le pedía era simplemente un informe de la mecánica usada en la provisión de los oficios.

\section{ARRENDAMIENTO DE OFICIOS}

Pero esto cambió radicalmente en 1720. El nuevo Corregidor e Intendente, don Juan de Vera Zúñiga y Fajardo, denunció a través de un Auto dado en Córdoba el 17 de junio la malversación de fondos municipales que suponía el nombramiento de personas particulares por parte de los Caballeros veinticuatros para el ejercicio de fiel romanero y otros oficios. Para el Intendente este modo de proveer los oficios públicos contradecía de una manera flagrante el artículo 37 de la Real Instrucción dada en San Lorenzo el 4 de julio de 1718, en el que se disponía la extirpación drástica de todo abuso en la administración de justicia y de cualquier tipo de dilapidación de los bienes de propios y efectos del "común». En el apartado 8. del mencionado artículo se alude expresamente a la malversación hecha por Capitulares que utilizaban indebidamente las alhajas de propios, como es el caso de los oficios adscritos a la ciudad (18).

Dispuesto el Corregidor a restituir a las arcas municipales lo que hasta aquel momento iba a parar a manos de particulares cuidadosamente elegidos por los Caballeros veinticuatros como si de cosa privada se tratara, por Auto de 2 de julio de 1720 alteró radicalmente la añeja costumbre, mandando sacar al pregón público los oficios pertenecientes a la ciudad, arrendarlos en los mayores y hábiles postores y aumentar la renta de propios con los precios en que se rematase la operación de arrendamiento. De esta forma el «entuerto» histórico quedaba arreglado, al convertir en beneficio del común lo que hasta entonces había sido una desvergonzada sinecura particular (19). Con esto se buscaba el saneamiento de la Hacienda municipal, pero también el recorte de viejas atribuciones de los Regidores en virtud de las cuales detentaban un poder efectivo en la medida en que hacían depender de ellos una numerosa clientela de potenciales beneficiados.

(18) Ibid., fols. 22r.-23v.

(19) Ibid., fols. 24r.-25v. 


\section{RECURSOS DE LOS CAPITULARES}

Ante este inesperado viraje, la reacción de los Caballeros veinticuatros fue moderada en un primer momento, como patentiza la proposición hecha en el Cabildo del 3 de julio de 1720 por el Conde de Arenales. En ella se abogaba por la restitución de lo sobrante de las rentas de los oficios, una vez deducidos los salarios, a los caudales del "común», se pedía que los Capitulares resarcirían a los propios las cantidades devengadas indebidamente, pero con la condición de que se suspendiese el Auto del Corregidor por el que ordenaba el arrendamiento de oficios, toda vez que este sistema produciría más males que bienes por la emulación, envidia e injusticias que conllevaba (20). Lo que trataba de cambiar esta propuesta era el destino de los beneficios de los oficios -ique ya no era poco!-, pero dejaba incólume la prepotencia de los Regidores al mantener el viejo sistema de sorteo y posterior nombramiento.

Evidentemente, ese no era el sentir del señor don Juan de Vera Zúñiga. El 13 de agosto de 1720 se hizo el primer pregón de arrendamiento. Y con él estalló de una manera abierta el conflicto entre los Caballeros veinticuatros y el Corregidor (21).

Los Caballeros veinticuatros acordaron en el Cabildo del 5 de julio de 1720 nombrar una comisión, que recayó en el citado Conde de Arenales y el Marqués de la Vega. Se les encomendó solicitar del Corregidor la suspensión del Auto por el que mandaba se procediese a los arrendamientos y consultar las provisiones y privilegios guardados en el Archivo, así como a los abogados de la ciudad (22). El Procurador Juan de Tena y Cáceres, en nombre de la comisión, hizo tres recursos. Dos de ellos, en 1720, y el tercero, en 1722. La argumentación empleada en los tres requerimientos se reducía sustancialmente a que la Real Provisión de 1717 no autorizaba al Corregidor a cambiar un sistema tradicional, que tenía una vigencia de más de cien años, por otro completamente nuevo. El informe recabado por aquella disposición no tenía nada que ver con una modificación tan radical en el modo de proveer los oficios. De ahí que, apoyándose en los privilegios y ordenanzas, se solicitase la anulación de los autos que ordenaban su arrendamiento y, en caso de proseguir, se declarase «nulidad por despojo e indefensión» (23).

(20) Ibid., fols. 26r.-28r.

(21) Ibid., fol. $28 \mathrm{v}$.

(22) Ibid., fol. 29r. y v.

(23) Ibid., fols. 31r. y v., 33r.-34v. 


\section{FIRMEZA DEL CORREGIDOR}

El Corregidor hizo caso omiso de estos reiterados requerimientos de la ciudad, a pesar de la barrera insalvable que los Regidores trataron de levantarle, boicoteando tres citaciones -14 y 24 de mayo y 5 de julio de 1721- a la Diputación de propios con el fin de hacer los remates (24). Incluso la no existencia de postor - «atenta la tenuidad de su producton (25) - no arredró al decidido Magistrado. En defecto de arrendatarios, «se sequestraron en diferentes personas que los sirbieren con la calidad de que tubieren quenta y razón del interés que prozediese de dichos oficios...» (26). El 7 de agosto de 1722 publicó otro Auto en el que obligaba a los fieles de los pesos de harina del Puente, Magdalena y Martos a exhibir los libros de cuentas y dar razón de su producto; o, en su lugar, jurar y declarar lo que valieron desde el día de San Juan de junio de 1720 (27). A toda costa y sin la menor concesión se propuso ingresar en las arcas municipales lo que él, en contra de los Regidores, consideraba alhajas de propios cuyos beneficios tenían que revertir necesariamente al "común».

En síntesis, los términos de este frontal antagonismo lo podíamos esquematizar así:

\section{Caballeros}

Veinticuatros $\quad \neq \quad$ Corregidores

a) OFICIOS PUBLICOS

- Sorteo $\quad \neq-$ Arrendamiento

b) PERSONAS

- Fidelidad y confianza

- Salario digno

$\neq-$ El mejor postor

$\neq$ - El que más pague a los propios

c) PRODUCTO

- Beneficio particular por servir bien $\neq$ - Beneficio municipal o público el oficio

$\begin{array}{ll}\text { - PODER LOCAL } & \neq \text { - CENTRALIZACION } \\ \text { - OLIGARQUIA ECONOMICA } & \neq \text { - HACIENDA MUNICIPAL }\end{array}$

(24) Ibid., fols. 38v., 39v. y 40r.

(25) Ver supra nota 10.

(26) AMCO: Oficios enajenados de la Corona, doc. 13, fol. $41 \mathrm{r}$.

(27) Ibid., fol. 42r. y v. 


\section{CONCLUSION}

La documentación utilizada no nos permite seguir el proceso hasta el final. No obstante, hechos posteriores, relacionados con la Administración local, testimonian la creciente invasión del absolutismo monárquico en las esferas locales, recortando notoriamente la autonomía que habían gozado en la época de los Austrias. En 1752, el Catastro de Ensenada certifica el triunfo de la línea del Corregidor o, lo que es lo mismo, del poder central, al dejar constancia de que los oficios enajenados de la Corona en favor de la ciudad de Córdoba están todos ellos arrendados y sus rentas forman una de las partidas que integran los ingresos municipales. Dos de los tres aspectos que señala Antonio Domínguez OrTIz como característicos del reformismo de Felipe $\mathrm{V}$ tuvieron obviamente sus connotaciones locales, como hemos elucidado en las líneas precedentes (28). Uno de ellos fue el intervencionismo económico que en el caso que nos ocupa se hace efectivo al aplicar el artículo 37 de la Real Instrucción de 1718. Preocupación primordial de esta disposición era el escrupuloso cuidado que los Corregidores debían tener de las Haciendas municipales. El otro, de carácter político, pero estrechamente vinculado con el anterior, de índole económico, consistió en reorganizar el aparato del Estado con la creación de los Intendentes. Precisamente don Juan de Vera Zúñiga y Fajardo, Corregidor e Intendente de Córdoba, consciente de su importante papel en la nueva singladura del Estado borbónico, se hará oídos sordos ante las reclamaciones de un Regimiento aristocrático en pro de la costumbre local en el nombramiento de oficios para imponer un nuevo sistema - arrendamiento de oficios- que, si bien tuvo como finalidad inmediata sanear las arcas municipales, sin embargo, apuntó mucho más lejos, al quebrar un hermético monopolio de poder por parte de los próceres locales (29).

(28) A. Domínguez Ortiz: Sociedad y Estado..., 84.

(29) Para Domf́nguez y Ortiz sólo las reformas municipales de Carlos III y Carlos IV tuvieron un matiz auténticamente reformista, porque la intentada por Felipe $\mathbf{V}$ la animaban más bien propósitos hacendísticos y absolutistas. Ibíd., 469. Por nuestra parte, creemos que esta tesis del clarividente historiador sevillano queda plenamente confirmada en el caso de Córdoba, como se desprende del cuerpo de este trabajo. 